BMJ Paediatrics Open

\section{Primary and secondary care approach to paediatric mental health conditions: a novel model of care}

To cite: Power E, Taaffe S, McLoughlin P, et al. Primary and secondary care approach to paediatric mental health conditions: a novel model of care. BMJ Paediatrics Open 2022;6:e001285. doi:10.1136/ bmjpo-2021-001285

- Additional supplemental material is published online only. To view, please visit the journal online (http://dx.doi.org/ 10.1136/bmjpo-2021-001285).

Received 19 September 2021 Accepted 14 January 2022
Check for updates

\section{(c) Author(s) (or their} employer(s)) 2022. Re-use permitted under CC BY-NC. No commercial re-use. See rights and permissions. Published by BMJ.

${ }^{1}$ University Hospital Limerick, Dooradoyle, Limerick, Ireland ${ }^{2}$ Department of Paediatrics, UCD School of Medicine, Dublin, Ireland

${ }^{3}$ Irish College of General Practitioners, Dublin, Ireland ${ }^{4} \mathrm{HSE}$, Dublin, Ireland ${ }^{5}$ Department of Paediatrics, Midland Regional Hospital Mullingar, Mullingar, Westmeath, Ireland

${ }^{6}$ Department of Paediatrics, Royal College of Surgeons in Ireland, Dublin, Ireland

\section{Correspondence to} Dr Edmond Power; edmond. power@ucdconnect.ie

\section{ABSTRACT}

The enforced isolation caused by the COVID-19 pandemic has led to an increase in mental health issues and severity of presentations to emergency departments in Ireland. Long waiting lists for both Psychology and Psychiatry are further impacting on children's mental well-being. We proposed the creation of a 'Happiness Toolkit' that can be given to children on presentation to their primary or secondary care provider with a mental health issue. The toolkit is comprised of six evidence-based techniques that are proven to boost self-esteem, develop resilience and promote positive mental health. A leaflet detailing the practices along with a physical 'box' that the children must make were created. This resource may therefore provide immediate support to those children that may endure long waiting periods, sometimes greater than a year and a half, for referral to tertiary services. Our toolkit allows children and their families to engage in positive mental health practices that may prevent regression during this waiting period and lead to improved mental health or cessation of symptoms.

\section{INTRODUCTION}

Ireland is facing a tsunami of mental health crises among the youth of our population as they struggle to deal with the repercussions of COVID-19 and its effects on society. The Growing Up in Ireland longitudinal study ${ }^{1}$ found that the proportion of young adults with elevated scores on a measure of depressive symptoms increased by $21 \%$ (48\% vs 27\%) compared with prepandemic levels. This has resulted in an increased severity of mental health presentations to emergency departments here and a higher admission rate. ${ }^{2}$ Healthcare providers are struggling to cope with this significant demand placed on an already strained health service. This has led to children being placed on increasingly long waiting lists for referral to specialist services, with some children waiting up to 80 weeks. ${ }^{34}$ Our suggested solution is to provide these children with a toolkit that contains practices to promote positive mental health. Children at risk of developing a mental health disorder are screened by their healthcare provider, provided with a toolkit if needed,

\section{Key messages}

- Mental health presentations among the paediatric population had increased in frequency and severity prior to the COVID-19 pandemic. This has since been compounded by the global pandemic.

- Waiting lists for specialist referral can be as long as 18 months.

- Primary and secondary healthcare providers are not adequately trained for dealing with mental health presentations in this young population.

- A 'tool-kit' of resources was created to be used at primary and secondary care level to bridge the gap.

and importantly, still referred to specialist services if so required. This toolkit aims to prevent children from deteriorating during the waiting period.

\section{CURRENT MANAGEMENT OF CHILDREN WITH MENTAL HEALTH DIFFICULTIES}

Once children are identified as having mental health difficulties, they are referred on to mental health services. Unfortunately, current estimates suggest that fewer than one in eight children with identified mental health problems, receive treatment. ${ }^{5}$ The waiting list for Primary Care Psychology has significantly increased with some patients waiting up to 80 weeks for an appointment and almost 5000 children and teenagers waiting more than 12 months. ${ }^{36}$ The latest figures in August 2021 from the Health Service Executive found that 2384 children were on the Child and Adolescent Mental Health Services waiting list for an appointment. ${ }^{7}$ Compounding this, a report published by Tusla, Ireland's Child and Family Agency, earlier this year showed a $48 \%$ monthly increase in the number of cases waiting to be dealt with by their Education Welfare Service. ${ }^{8}$ It is clear then that there is a disparity between when children are referred and when they will actually be seen and receive interventions by mental health services. 
Public health nurses, general practitioners and paediatricians typically struggle to maintain and support these families in the community while on waiting lists; however, they can be an invaluable resource to help patients and parents gain strategies for developing self-care skills and build resilience to help cope with adversity. This will also help to destigmatise the conversation around mental health. This approach intends to complement the work rolled out by the Department of Education and Skills where social emotional health has become an important facet of a child's education. ${ }^{9}$

\section{OUR SOLUTION: BOX OF HAPPINESS MENTAL HEALTH RESOURCE TOOLKIT}

We propose using sensitive and specific tools to identify social emotional behavioural mental health problems such as the ASQ and Paediatric Symptom Checklist. ${ }^{10} 11$ Our solution to support the growing number of children on waiting lists for mental health intervention is to equip children and young adults in the community with a set of tools and resources so that they are provided with practical support while awaiting treatment or on waiting lists. The Paediatric Clinic at Mullingar Regional Hospital, Ireland has used the 'Box of Happiness' Resource Tool Kit for Children as a means to boost well-being, improve mental health and support children and young people with mental health dysregulation and challenges. Anecdotal feedback has been positive and has benefited and supported children and their families as they await specialist interventions. The main components of the box are psychoeducational, allowing children and young people to work through different activities that are aimed at improving well-being.

The supervising author has used these techniques for the past number of years in her clinic using a two and three generational approach with success. In an effort to address the healthcare training gap in paediatric mental health, an e-module is under development to complement the roll-out of this toolkit. An accompanying instructional video for the children and their caregivers explaining the different components of the toolkit and the neuroscience behind it, is also under development.

\section{WHAT ARE THE COMPONENTS?}

\section{Smile a vision}

Having a vision or having a purpose has been shown to predict both health and longevity and may be a mechanism underlying resilience, offering protection from negative events. ${ }^{12}$ Children are shown how to visualise themselves in the future, whether it is the short-term, such as spending time with someone that they trust, or long-term by visualising themselves achieving a goal such as playing for a team or improving in a particular field. A study by the American Psychological Association that followed children over the course of 18 years found that those who did not give up on their goals had less anxiety and depression. ${ }^{13}$ Children are encouraged to smile while visualising happy memories or future aspirations to further promote the positive mental health benefits (online supplemental appendix 1$).{ }^{14}$

\section{Friends and family and social relatedness}

The need to belong and be loved by others has been well documented throughout history and is placed above only safety and physiological needs in Maslow's Hierarchy of Needs. ${ }^{15}$ Children, as well as their parents, are encouraged to spend time with each other and participate in activities such as sports or community-organised events. The 5Rs are recognised pillars of healthy brain development in infancy and early childhood. These include Reading, Rhyming, Routine, Reward and Relationships. ${ }^{16}$

In the era of technology, working from home and increasing device use, it is important that parents appreciate the value in being present when around their children. Technology is now such an integral part of our lives; it can enhance connectivity and education but can also significantly impact on well-being and health if used inappropriately or in excess. ${ }^{17}$ Supportive direction and education around screen-time can be of great benefit. Primary care providers can guide parents to navigate the digital world with their children in a responsible manner and with insight, preventing issues like behaviour addiction to screens and cyber bullying which is increasing resulting in anxiety, depression and self-harm in children. $^{18}$

\section{Mindfulness}

Mindfulness has been shown to bring about various positive psychological effects, including increased subjective well-being, reduced psychological symptoms and emotional reactivity and improved behavioural regulation. ${ }^{19}$ Children are encouraged to use slow, deep breathing, also known as diaphragmatic breathing, which has been shown to have a wide range of positive benefits, from increased comfort and relaxation, to decreased anxiety and depression. ${ }^{20}{ }^{21}$ Mindfulness can be taught to all children in an age-appropriate manner. Practicing mindfulness can also take many forms, such as tapping into creativity or walking and exploring in nature; appreciating the beauty of our natural surroundings offers many health benefits. Evidence shows that nature itself can boost our well-being. ${ }^{22}$ There are many simple ageappropriate mindful activities that can be adopted to allow children of all ages to integrate this coping mechanism into their routine, in a very natural way. We share a selection of activities to support this practice.

\section{Gratitude}

Children who experience gratitude are happier as it is associated with greater well-being and improved social relationships. ${ }^{2324}$ Gratitude can take the form of a 'Happy Diary' where children write down what made them happy during the day or start the day by writing down three things to be happy or grateful for. This reinforces positive 
thoughts, and the associated shift in brain biochemistry that this causes promotes well-being. ${ }^{25}$

\section{Hugs and physical contact}

Parents should be encouraged to hug their children when engaging in activities such as reading a night-time story book or practicing mindfulness as social touch has been shown to reduce maladaptive responses such as stress. ${ }^{26}$ Hugging and positive physical contact sets the oxytocin cascade, often known as the 'hug hormone' in motion, which promotes well-being and connectivity.

\section{Understanding emotions}

The 'Hand Model of the Brain'27 created by Dr Dan Siegel is used to explain to children and parents how their reactions are influenced by their emotions with the phrase 'Name it to Tame it'. This can be explained in clinic so that both children and parents have a physical representation of their mind which allows them to 'name' their emotion instead of simply reacting to it.

\section{TARGET POPULATION}

This tool kit may benefit children across a broad demographic, presenting with mental health concerns in a costeffective manner, and may be used in both primary and secondary care. Primary care clinics, paediatric outpatient departments and even the paediatric emergency department are potential first contact points with these children and an opportunity to offer support via this tool. The tool kit is suitable for children who are older than the age of 5 while also possessing the capacity to understand the concepts it contains. For those less than 5 years of age, the components of the box can be taught to parents so that they may work with their child to develop positive mental health practices.

\section{WHY IS IT SO IMPORTANT?}

Children with mental illness become adults with mental illness. The first onset of mental disorders usually occurs in childhood or adolescence. ${ }^{28}$ If adequate resources are available and children are taught skills to develop resilience, then there is greater chance of them overcoming adverse events in their lives and preventing mental health issues from progressing into adulthood. Mental health disorders constitute a significant economic burden for societies. ${ }^{29}$ Such a burden could be lessened by investing in the mental health of our youth at a primary care level. The COVID-19 pandemic has also compounded this problem as it has led to fears of regression in children, as expressed by the Children's Ombudsman recently. ${ }^{30}$ Studies from various fields including neurobiology, neurodevelopment and early intervention have shown that birth to 5 years of ages is a crucially important time in brain development and has lifelong effects on mental health. ${ }^{31}$ The focus is shifting favourably towards maternal and infant mental health, particularly in the first 1000 days of life, and the realisation that robust social emotional health in children is critical for building resilience and the ability to overcome challenges to mental health.

\section{CONCLUSION}

Improving social and emotional health of children can have long-term beneficial effects on their well-being. It is therefore of utmost importance that primary care providers, public health nurses, general practitioners as well as paediatricians understand the importance of supporting and promoting positive infant and child mental health. There exists a gap in the training for evaluation and management of common mental health disorders in this population at primary and secondary care level $^{32}$ and the COVID-19 Pandemic has enhanced our realisation of this stark reality, with worsening of the mental health crisis. ${ }^{33}$

It is of paramount importance therefore that tools that are cost effective, user friendly and easily taught, are incorporated in everyday practice at primary and secondary care levels. The 'Box of Happiness' Resource Tool Kit for Children allows those in need to focus on the positive aspects of their lives and form beneficial habits, while building resilience. This toolkit is closely aligned with the 'Mental Health Competencies for Pediatric Practice' recommended by the American Academy of Pediatrics. ${ }^{34}$ Such interventions will lead to long-term benefits for our children and can have a significant transgenerational impact on prevention of future mental health disorders.

Anecdotally, it is evident that those who have used the toolkit have reported enhanced well-being in their families and children as they await additional intervention, empowering them to improve aspects that they can take control of. It is recognised that a rigorous study to objectively measure these benefits is needed, in addition to a structured programme to educate all healthcare practitioners dispensing the toolkit to these patients. The authors aim to complete a pilot study to assess these interventions further. Given the potential benefits and the strong evidence base of each individual component, we anticipate that this simple resource kit will make an impact on those awaiting intervention.

Contributors EP, ST and FS contributed equally to the: design and analysis of the work; drafting the work and revising it critically; approving the final version and agreeing to be accountable for all aspects of the work. EP drafted, researched and revised the paper and the creation of the toolkit resource. FS developed the original idea for this project, created the toolkit from resources used in her own paediatric clinic and revised the draft papers. ST provided input for the creation of the toolkit, designed the toolkit and revised the draft papers. PM reviewed the original draft and provided feedback on the use of the resource in healthcare settings.

Funding The authors have not declared a specific grant for this research from any funding agency in the public, commercial or not-for-profit sectors.

Competing interests None declared.

Patient and public involvement Patients and/or the public were not involved in the design, or conduct, or reporting, or dissemination plans of this research. 
Patient consent for publication Not applicable.

Provenance and peer review Not commissioned; externally peer reviewed.

Data availability statement Data sharing not applicable as no datasets generated and/or analysed for this study. Not applicable.

Supplemental material This content has been supplied by the author(s). It has not been vetted by BMJ Publishing Group Limited (BMJ) and may not have been peer-reviewed. Any opinions or recommendations discussed are solely those of the author(s) and are not endorsed by BMJ. BMJ disclaims all liability and responsibility arising from any reliance placed on the content. Where the content includes any translated material, BMJ does not warrant the accuracy and reliability of the translations (including but not limited to local regulations, clinical guidelines, terminology, drug names and drug dosages), and is not responsible for any error and/or omissions arising from translation and adaptation or otherwise.

Open access This is an open access article distributed in accordance with the Creative Commons Attribution Non Commercial (CC BY-NC 4.0) license, which permits others to distribute, remix, adapt, build upon this work non-commercially, and license their derivative works on different terms, provided the original work is properly cited, appropriate credit is given, any changes made indicated, and the use is non-commercial. See: http://creativecommons.org/licenses/by-nc/4.0/.

ORCID iD

Edmond Power http://orcid.org/0000-0002-9788-1937

\section{REFERENCES}

1 Esri T. Growing up in Ireland national longitudinal study of children. Available: https://www.growingup.ie/

2 McDonnell T, Nicholson E, Conlon C, et al. Assessing the impact of COVID-19 public health stages on paediatric emergency attendance. Int J Environ Res Public Health 2020;17:2020-09-15:6719.

3 O'Halloran M. Almost 5,000 children waiting on psychology services to be seen this year under new plan. Available: https:// www.irishtimes.com/news/politics/almost-5-000-children-waitingon-psychology-services-to-be-seen-this-year-under-new-plan-1. 4483580

4 Michael N. Children with mental health issues forced to wait up to 18 months for help, 2020. Available: https://www.irishexaminer.com/ news/arid-40148987.html

5 Weitzman C, Wegner L, et al, Section on Developmental and Behavioral Pediatrics. Promoting optimal development: screening for behavioral and emotional problems. Pediatrics 2015;135:384-95.

6 Corcoran M, Byrne M. Evaluating a primary care psychology service in Ireland: a survey of stakeholders and psychologists. Health Soc Care Community 2017;25:1080-1089.

7 Bermingham D. 170 children waiting more than a year for mental health services, 2021. Available: https://www.irishexaminer.com/ news/arid-40738515.html

8 Baker N. Tusla sees child welfare and protection referrals rise to highest level in a year, 2021. Available: https://www.irishexaminer. com/news/arid-40225766.html

9 Go I. Wellbeing policy statement and framework for practice. Available: https://assets.gov.ie/24725/07cc07626f6a426eb6eab4c5 23fb2ee2.pdf

10 Briggs RD, Stettler EM, Silver EJ, et al. Social-emotional screening for infants and toddlers in primary care. Pediatrics 2012;129:e377-84.

11 Murphy JM, Bergmann P, Chiang C, et al. The PSC-17: Subscale scores, reliability, and factor structure in a new national sample. Pediatrics 2016;138:e20160038.
12 Schaefer SM, Morozink Boylan J, van Reekum CM, et al. Purpose in life predicts better emotional recovery from negative stimuli. PLoS One 2013;8:e80329.

13 Zainal NH, Newman MG. Relation between cognitive and behavioral strategies and future change in common mental health problems across 18 years. J Abnorm Psychol 2019;128:295-304.

14 Fredrickson BL. The role of positive emotions in positive psychology. The broaden-and-build theory of positive emotions. Am Psychol 2001;56:218-26.

15 Maslow A. Maslow's hierarchy of needs - Oxford Reference, 1943.

16 High PC, American Academy of Pediatrics Committee on Early Childhood, Adoption, and Dependent Care and Council on School Health. School readiness. Pediatrics 2008;121:e1008-15.

17 Radesky JS, Christakis DA. Increased screen time: implications for early childhood development and behavior. Pediatr Clin North Am 2016;63:827-39.

18 Abi-Jaoude E, Naylor KT, Pignatiello A. Smartphones, social media use and youth mental health. CMAJ 2020;192:E136-41.

19 Keng S-L, Smoski MJ, Robins CJ. Effects of mindfulness on psychological health: a review of empirical studies. Clin Psychol Rev 2011;31:1041-56.

20 Russo MA, Santarelli DM, O'Rourke D. The physiological effects of slow breathing in the healthy human. Breathe 2017;13:298-309.

21 Zaccaro A, Piarulli A, Laurino M, Garbella M, et al. How BreathControl can change your life: a systematic review on Psychophysiological correlates of slow breathing. Front Hum Neurosci 2018;12:353

22 White MP, Alcock I, Grellier J, et al. Spending at least 120 minutes a week in nature is associated with good health and wellbeing. Sci Rep 2019;9:1-11.

23 Nguyen SP, Gordon CL. The relationship between Gratitude and happiness in young children. J Happiness Stud 2020;21:2773-87.

24 Layous K, Lyubomirsky S, Suldo S. Benefits, mechanisms, and new directions for teaching Gratitude to children. School Psych Rev 2014;43:153-9.

25 Emmons RA. Psychology of Gratitude: An Introduction - Oxford Scholarship, 2004.

26 Morrison I. Keep calm and Cuddle on: social touch as a stress buffer. Adapt Human Behav Physiol 2016;2:344-62.

27 Siegel DD. Hand Model of the Brain - Dr. Dan Siegel. Available: https://drdansiegel.com/hand-model-of-the-brain/

28 Kessler RC, Berglund P, Demler O, et al. Lifetime prevalence and age-of-onset distributions of DSM-IV disorders in the National comorbidity survey replication. Arch Gen Psychiatry 2005;62:593602.

29 Christensen MK, Lim CCW, Saha S, et al. The cost of mental disorders: a systematic review. Epidemiol Psychiatr Sci 2020;29:e161.

30 Libreri S. Concern for regression of children in pandemic. article. @ rte. Updated 2021-02-13T19:53:26+00:00. Available: https://www. rte.ie/news/coronavirus/2021/0213/1196928-childrens-ombusman/

31 Cooper BW, Luddy P, Daley, M S. Engaging families in the early childhood development story: a national project conducted on behalf of the Ministerial Council for education. Early Child Dev Youth Aff 2010.

32 Fitzgerald E, Foley D, McNamara R, et al. Trends in mental health presentations to a paediatric emergency department. Ir Med J 2020;113:20.

33 O'Connor K, Wrigley M, Jennings R, et al. Mental health impacts of COVID-19 in Ireland and the need for a secondary care mental health service response. Ir J Psychol Med 2021;38:99-107.

34 Foy JM, Green CM, Earls MF, et al. Mental health competencies for pediatric practice. Pediatrics 2019;144. doi:10.1542/peds.20192757. [Epub ahead of print: 21 Oct 2019] 